\title{
Extended Kalman filter based statistical orbit determination for geostationary and geosynchronous satellite orbits in BeiDou constellation
}

\author{
Radhika A. CHIPADE ${ }^{1,2, *}$ (D), Thekke Variyam RAMANATHAN² (D) \\ ${ }^{1}$ Space Applications Centre (ISRO), Ahmedabad - 380015, India, \\ e-mail: radhikachipade@gmail.com \\ ${ }^{2}$ Department of Statistics, Savitribai Phule Pune University, Pune - 411007, India, \\ e-mail: ram@unipune.ac.in
}

\begin{abstract}
BeiDou Navigation Satellite System (BDS) is composed of satellites in geostationary Earth orbit (GEO), medium Earth orbit (MEO) and inclined geosynchronous orbit (IGSO). However, the orbit determination of geostationary Earth orbits and of geosynchronous orbits (GSO) with small inclination angle and small eccentricity is a challenging task that is addressed in this paper using Extended Kalman Filter (EKF). The satellite positions were predicted in Earth-centred inertial (ECI) reference frame when propagated through Keplerian model and perturbation force model for different values of right ascension of ascending node (RAAN). Root mean square (RMS) errors of $9.61 \mathrm{~cm}$, $6.73 \mathrm{~cm}$ and $11.46 \mathrm{~cm}$ were observed in ECI X, Y and Z satellite position coordinates of GSO respectively, whereas, the RMS errors for GEO satellite were $8.89 \mathrm{~cm}, 7.92 \mathrm{~cm}$, and $0.93 \mathrm{~cm}$ respectively in ECI $\mathrm{X}, \mathrm{Y}$ and $\mathrm{Z}$ coordinates; for perturbation force model with maximum value of RAAN when compared with dynamic orbit determination model. Kolmogorov-Smirnov test for EKF reported a $p$-value $>0.05$, indicating a good fit of perturbation force model for orbit propagation. Orbit determination using EKF with perturbation force model were compared with that using EKF with Kepler's model. Wilcoxon Rank Sum test was used to compare the residuals from EKF algorithm through Kepler's model and perturbation force model. EKF with Perturbation force model showed improvement in predicting the satellite positions as compared to Kepler's model. EKF with Perturbation force model was further applied to International GNSS Service (IGS) station data and kilometre level accuracy was achieved. RMS errors of $0.75 \mathrm{~km}, 2.53 \mathrm{~km}$ and $1.91 \mathrm{~km}$ were observed in ECI X, Y and Z satellite position coordinates of GSO, respectively, whereas, the RMS errors for GEO satellite were $3.89 \mathrm{~km}, 4.20 \mathrm{~km}$ and $6.66 \mathrm{~km}$ respectively in ECI $\mathrm{X}, \mathrm{Y}$ and $\mathrm{Z}$ coordinates for perturbation force model.
\end{abstract}

Key words: BeiDou, extended Kalman filter, geostationary Earth orbit, geosynchronous orbit, statistical orbit determination, Wilcoxon rank sum test

\footnotetext{
*corresponding author: e-mail: radhikachipade@gmail.com
} 


\section{Introduction}

Satellite positions are essential to estimate positioning solution in navigation. However, acquisition of the satellite signal to attain position fix by a navigation receiver is a challenging task with environments such as underground parking bays, closed buildings, areas with dense plantation and so on. One of the ways to solve this problem is to estimate the orbital parameters and hence the satellite positions locally at the receiver using statistical orbit determination techniques. Orbit determination is the process of estimating the state of a satellite whose initial state is unknown based on the observations that are influenced by random and systematic errors (Tapley et al., 2004).

Statistical orbit determination algorithm can be divided into two main tasks: orbit prediction (or propagation) and orbit determination. The orbit prediction algorithm utilizes a set of force models and a numerical integration technique to predict the state of the satellite at time $t_{k}$ if the state of the satellite at some initial epoch time $t_{0}$ is known. The statistical orbit determination algorithm modifies the state of the satellite at the start of the orbit prediction. The statistical orbit determination algorithm can be used to help the orbit prediction algorithm to improve the accuracy of the predicted state of the satellite.

Various statistical orbit determination algorithms have been reported in the literature for different navigation constellations. A simulation study of orbit determination using Extended Kalman filter (EKF) has been reported for geosynchronous satellites of a European Satellite Navigation System (ENSS) in Hein et al. (1997). This study used the navigation data from 8 tracking stations all over the world. Davis et al. (2002) have reported Global Positioning System (GPS)-based orbit determination of highly elliptical orbit using data collected from a Trimble Advanced Navigation Sensor (TANS) Vector receiver with an accuracy of kilometre $(\mathrm{km})$ level. The Least-Squares based approach for orbit determination of GPS satellites has been reported in Seppänen et al. (2011), which demonstrates the technology for mobile devices. Hwang et al. (2013) have reported geostationary orbit determination using a single station data with km level accuracy. Aghav and Gangal (2014) have made an attempt to compare Least-Squares and Kalman filter for orbit determination of a satellite in low-Earth orbit. This study reported prediction up to 60 seconds with an accuracy of km level. Adaptive Kalman filter 
was used for orbit determination of GSAT-10 and IRNSS-1A (now NavIC 1-A) satellites (Kavitha et al., 2015). This study used 4 two-way code division multiple access (CDMA) range stations' data in India. A simulation study of orbit prediction algorithm for maximum up to 1 hour was demonstrated for IRNSS 1D, 1E, 1F and $1 \mathrm{G}$ (now NavIC 1D, 1E, 1F, 1G) satellites (Chandrasekhar et al., 2015). The statistical orbit determination algorithm for NavIC satellites in Geosynchronous (GSO) and Geostationary (GEO) orbits using EKF was developed by Ramanathan and Chipade (2020) up to metre-level accuracy. This problem of statistical orbit determination in the context of GNSS (Global Navigation Satellite System) is known as Extended Ephemeris Technology. Ephemeris extension algorithm for BeiDou Navigation Satellite System (BDS) orbits using Least Squares technique have been reported in Shen et al. (2018). They use the precise ephemeris orbit products for the calibration of satellite orbits. These authors have reported $\mathrm{km}$ level accuracy in radial direction of GEO satellite. However, they did not consider the GEO satellites of BDS constellation for the orbit determination. On the other hand, they have reported the prediction of MEO and IGSO satellites of BDS using precise orbit and clock products available through Multi-Global Navigation Satellite Systems (GNSS) Pilot Project (MGEX), which are not available in real time. Precise orbit and clock products are available through IGS/MGEX with a delay of 14 days (Kazmierski et al., 2020). Orbit determination of BDS satellites using better algorithms such as EKF is still not attempted. Further scanty literature is available on statistical orbit determination techniques applied to Geostationary and Geosynchronous orbits with reference to observations from single station data rather than from a network for BDS GSO and GEO orbits. Thus, this is the only study that reports the extended ephemeris technology for BDS receivers in real time with km level accuracy.

The present study reports a statistical orbit determination algorithm using EKF with perturbation force model for GSO and GEO orbits of BeiDou navigation satellite system. This is the first attempt to predict BDS GSO and GEO orbits using EKF with perturbation force model that can be used for the development of self-assisted ephemeris technology for BeiDou receivers. The methodology is discussed in section 2 followed by results and discussion and conclusions in section 3 and section 4 , respectively. 


\section{Methodology}

\subsection{Statistical orbit determination algorithm}

In the present study, the orbit prediction algorithm was developed using $4^{\text {th }}$ order Runge-Kutta numerical integration method, whereas EKF was used as orbit determination algorithm.

If the satellite position vector $\vec{r}=(x, y, z)^{T}$ and velocity vector $\vec{v}=$ $\left(v_{x}, v_{y}, v_{z}\right)^{T}$ are known in Earth-Centered-Inertial (ECI) reference frame at some initial epoch $t_{0}$ then the initial state vector used for orbit prediction algorithm becomes $\vec{X}=\left(x, y, z, v_{x}, v_{y}, v_{z}\right)^{T}$. Let $r$ and $v$ be the magnitude of the satellite position vector and velocity vector, respectively. The initial state vector $\vec{X}\left(t_{0}\right)$ was computed in ECI reference frame using single ephemeris data that was available at initial epoch $t_{0}$. In general, state vector at time $t$ was denoted as $\vec{X}(t)$.

The set of force models that determine the acceleration of the satellite due to various effects is:

$\vec{a}=-\frac{\mu \vec{r}}{r^{3}}+\vec{a}_{h a r}+\vec{a}_{\text {sun }}+\vec{a}_{\text {moon }}+\vec{a}_{\text {srp }}+\vec{a}_{\text {tides }}+\vec{a}_{r e l}$,

where the Kepler's force model can be written as:

$\vec{a}=-\frac{\mu \vec{r}}{r^{3}}$,

with

$\mu$ : Earth's gravitational constant $\left(3.986004418 \cdot 10^{14} \mathrm{~m}^{3} / \mathrm{s}^{2}\right)$,

$\vec{a}_{\text {har }}$ : acceleration due to Earth's gravity potential,

$\vec{a}_{\text {sun }}$ : acceleration due to solar attraction,

$\vec{a}_{\text {moon }}$ : acceleration due to lunar attraction,

$\vec{a}_{\text {srp }}$ : acceleration due to solar radiation pressure,

$\vec{a}_{\text {tides }}$ : acceleration due to Earth tidal effect and

$\vec{a}_{r e l}$ : acceleration due to relativistic effects.

The acceleration due to Earth's gravity potential (geopotential) was modelled using spherical harmonic expansion as given in Eqs. (3) and (4) (Stacey and Ziebart, 2011). The acceleration due to Earth's oblateness (zonal perturbation J2) is the most significant perturbation force acting on GEO and GSO as compared to lower order geopotential (Hein et al., 1997). Carolipio et al. (2002) have achieved orbit determination of GEO satellite with accu- 
racy comparable to GPS satellites considering only Earth's oblateness as perturbation force model. Seppänen et al. (2011) have reported that for GNSS satellite altitudes, geopotential up to degree 4 is significant. Shen et al. (2018) have reported $30 \times 30$ geopotential model for GEO achieving satellite prediction accuracy of $41 \mathrm{~km}$ in radial direction.

The aim of the present study is to develop an algorithm that can predict satellite orbit locally at the receiver and thus a computationally suitable model that balances model complexities and computational accuracy is needed (Zhang et al., 2008). Geopotential coefficients of order 0 are called as zonal coefficients. It is important to note that geopotential coefficient $\mathrm{J} 2$ is about 400 times larger than the next-largest value of geopotential coefficient J3 and thus for most satellite orbits reasonable good accuracy is achieved by including only $\mathrm{J} 2$ effect in the perturbation force model (Chobotov, 2002, chapter 9, p. 204). Thus, geopotential model of order 0 and degree 4 was considered in the present study. The values of geopotential coefficients in the system WGS-84 were considered as J2 $=1082.63 \cdot 10^{-6}$, $\mathrm{J} 3=-2.5321531 \cdot 10^{-6}$ and $\mathrm{J} 4=-1.6109876 \cdot 10^{-6}$ (Chobotov, 2002, chapter 9, p. 205). Note that:

$\vec{a}_{h a r}=\vec{\nabla} U$

where $U$ is the gravitational potential, modelled as (Stacey and Ziebart, 2011):

$U=\frac{\mu}{r} \sum_{n=0}^{\infty} \sum_{m=0}^{\infty}\left(\frac{R_{e}}{r}\right)^{n} P_{n m}(\sin (\phi))\left[C_{n m} \cos (m \lambda)+S_{n m} \sin (m \lambda)\right]$,

with $R_{e}$ as the Earth's radius, $\phi$ and $\lambda$ as the latitude and longitude of the satellite position. $P_{n m}$ is the associated Legendre polynomial of degree $n$ and order $m . C_{n m}$ and $S_{n m}$ are the tesseral harmonics coefficients. The explicit equations for solving geopotential acceleration are given in Chobotov (2002; chapter 9, p. 202) and Aghav and Gangal (2014).

The acceleration due to solar and lunar attraction forces was modelled using Newton's law of gravitational attraction for a point mass as given in Eqs. (5) and (6), respectively as:

$\vec{a}_{\text {sun }}=\mu_{\text {sun }}\left(\frac{\vec{r}_{\text {sun }}-\vec{r}}{\left|\vec{r}_{\text {sun }}-\vec{r}\right|^{3}}-\frac{\vec{r}_{\text {sun }}}{\left|\vec{r}_{\text {sun }}\right|^{3}}\right)$, 
$\vec{a}_{\text {moon }}=\mu_{\text {moon }}\left(\frac{\vec{r}_{\text {moon }}-\vec{r}}{\left|\vec{r}_{\text {moon }}-\vec{r}\right|^{3}}-\frac{\vec{r}_{\text {moon }}}{\left|\vec{r}_{\text {moon }}\right|^{3}}\right)$,

where $\mu_{\text {sun }}$ and $\mu_{\text {moon }}$ are the solar and lunar gravitational constants, respectively. The vectors $\vec{r}_{\text {sun }}$ and $\vec{r}_{\text {moon }}$ are the geocentric vectors of the Sun and the Moon, respectively.

The Cannonball type solar radiation pressure model is given by Eq. (7):

$\vec{a}_{\text {srp }}=\mu_{s} P_{o} C_{r} \frac{A}{m}(\mathrm{AU})^{2} \frac{\vec{e}_{\text {sun }}}{r_{\text {sun }}^{3}}$,

where $\mu_{s}$ is the shadow factor; AU is the astronomical unit (149597870.691 $\mathrm{km}) ; P_{o}$ is the solar radiation pressure at distance of $1 \mathrm{AU}$ from the sun $\left(4.56 \cdot 10^{-6} \mathrm{~N} . \mathrm{m}^{-2}\right) ; C_{r}$ is the reflectivity coefficient of the satellite; $A$ is the surface area of the satellite and $m$ is the mass of the satellite. The vector $\vec{e}_{\text {sun }}$ is the unit vector from satellite to the Sun and $r_{\text {sun }}$ is distance from satellite to the Sun. We use the Cannonball type solar radiation pressure model for GPS, Galileo, BeiDou and NavIC as considered by (Hein et al., 199\%; Stacey and Ziebart, 2011; Shen et al. 2018; Ramanathan and Chipade 2020).

Other forces like Earth's tidal effect and relativistic effects were also included for orbit prediction. The acceleration due to Earth's tidal effect was modelled using spherical harmonic expansion as given in Montenbruck and Gill (2005; chapter 3, p. 108). Legendre polynomial of order 3 and degree 5 was considered for modelling Earth's tidal effect in the present study. Addition of these two perturbation forces did not yield any significant improvement in the orbit determination of GEO and GSO satellites of BDS, details of which are given in subsequent section. The details of modelling tidal effects and relativistic effects are as given in Montenbruck and Gill (2005; chapter 3, p. 110).

Statistical orbit determination algorithm uses the knowledge of dynamics model as well as observation model. Dynamics model includes deriving equations of motion of the satellite, whereas the observation model uses measurements from the observing instruments like receiver. EKF was used to estimate the state vector $\vec{X}(t)$, when the distribution of state parameters is Gaussian for a non-linear dynamics model. EKF also estimates the posterior covariance associated with estimate $\hat{X}_{k} ; P\left(t_{k}\right)$ that quantifies the 
uncertainty of the state estimate. We refer to Mashiku (2013) and Ramanathan and Chipade (2020) for more details.

The algorithm was initialised with an initial state vector $\hat{X}_{0}$ computed based on previously known orbital parameters and an a priori covariance associated with state estimate, $P_{0}$; for a dynamics model of orbit determination.

At time $t_{k}$, the state vector and the error covariance was computed using the state transition matrix $A$. Thus:

$\hat{X}_{k}^{-}=A \hat{X}_{k-1}$,

$P_{k}^{-}=A P_{k-1} A^{T}+Q$,

where, $Q$ is the diagonal, process noise covariance matrix and $A$ is the state transition matrix given by:

$A=I_{6 \times 6}+\left[\begin{array}{cccccc}0 & 0 & 0 & 1 & 0 & 0 \\ 0 & 0 & 0 & 0 & 1 & 0 \\ 0 & 0 & 0 & 0 & 0 & 1 \\ -\frac{\mu}{r^{3}}+\frac{3 \mu x^{2}}{r^{5}} & \frac{3 \mu x y}{r^{5}} & \frac{3 \mu x z}{r^{5}} & 0 & 0 & 0 \\ \frac{3 \mu x y}{r^{5}} & -\frac{\mu}{r^{3}}+\frac{3 \mu y^{2}}{r^{5}} & \frac{3 \mu y z}{r^{5}} & 0 & 0 & 0 \\ \frac{3 \mu x z}{r^{5}} & \frac{3 \mu y z}{r^{5}} & -\frac{\mu}{r^{3}}+\frac{3 \mu z^{2}}{r^{5}} & 0 & 0 & 0\end{array}\right] \mathrm{d} t$.

The Kalman gain $K_{k}$ was computed from the observation models using the $H$-matrix, given in Eq. (11). Thus:

$K_{k}=P_{k}^{-} H^{T}\left(H P_{k}^{-} H^{T}+R\right)^{-1}$,

$H=\frac{\partial G}{\partial X}$,

where $G(X, t)=[r(t)], r(t)=\sqrt{\left(x-x_{0}\right)^{2}+\left(y-y_{0}\right)^{2}+\left(z-z_{0}\right)^{2}}$ and $\left(x_{0}\right.$, $\left.y_{0}, z_{0}\right)$ are the coordinates of the receiver or the sensor on ground which were assumed to be known. In this study, the distance of the satellite from the centre of Earth was considered as the $r(t)$, to make the algorithm simplified and autonomous, independent of any receiver observable. Thus, $\left(x_{0}, y_{0}, z_{0}\right)$ was considered to be $(0,0,0)$. $R$ is the measurement covariance. 
The state estimate is updated using the Kalman gain and the innovation term $\left(Y_{k}-H \hat{X}_{k}^{-}\right)$, where $Y_{k}$ was actually observed satellite range at time $t_{k}$. Thus:

$\hat{X}_{k}=\hat{X}_{k}^{-}+K_{k}\left(Y_{k}-H \hat{X}_{k}^{-}\right)$,

$P_{k}=\left(I-K_{k} H\right) P_{k}^{-}$.

\subsection{Criterion used for the evaluation of predicted orbit accuracy}

The root mean square error (RMS error or RMSE) was used in the present study to evaluate the orbit accuracy. The predicted satellite coordinates using the statistical orbit determination algorithm were compared with satellite coordinates generated through simulation using force model as given by Eq. (1). RMS error was computed using the Eq. (13). Note that:

$\mathrm{RMSE}=\sqrt{\frac{\sum_{i=1}^{T}\left(Q_{i, \text { pred }}-Q_{i, a c t}\right)^{2}}{T}}$,

where $T$ is the total duration over which the orbit is predicted. Here, $T=86400$, as the orbit predicted for next one day at an interval of 1 sec. The quantities $Q_{\text {pred }}$ and $Q_{\text {sim }}$ are the predicted and simulated satellite coordinates in ECI reference frame, respectively.

The Kolmogorov-Smirnov (K-S) test is a non-parametric test that can be used to compare two probability distributions by quantifying the distance between the empirical cumulative distribution functions of two samples. $\mathrm{K}-\mathrm{S}$ test was used to assess the goodness of fit of orbit prediction algorithm viz., EKF. Wilcoxon Rank Sum (WRS) test can be used to compare two populations for their identicalness using the corresponding samples from them. Here, we compare the residuals for EKF algorithm through Kepler's orbit and perturbation force model.

\section{Results and discussion}

Coordinates of satellites in GEO and GSO orbits of BDS constellation were estimated using proposed EKF algorithm. The orbit determination was carried out in two parts with two different datasets: (a) orbit determination 
using EKF of GEO and GSO orbits at time interval of 1 sec. for an assumed set of orbital parameters of BDS constellation spanning all possible right ascension of ascending node (RAAN) values and (b) orbit determination using EKF of real time GEO and GSO orbits as recorded at International GNSS Service (IGS) station for 5 days, at time interval of $60 \mathrm{sec}$.

\subsection{Orbit determination with assumed set of orbital parameters of BDS GEO and GSO orbits}

The GEO and GSO satellite orbits of BDS constellation were determined for a total period of one day ( $T=86400 \mathrm{sec})$ using Kepler's force model and perturbation force model as given by Eq. (1), at the interval of $1 \mathrm{sec}$. The set of orbital parameters used for orbit determination is as given in Table 1. The values of RAAN were varied at $0^{\circ}, 120^{\circ}$, and $240^{\circ}$. The values of orbital parameters were selected to address all possible orientations of geostationary and geosynchronous orbits in BDS constellation (Huang and Tsai 2008; Xiaoganag and Mingquan, 2017). The satellite position estimated in ECI reference frame using these orbital parameters at time $t_{0}$ was considered as the initial guess for orbit determination algorithm using EKF. EKF was used as a statistical orbit determination technique to estimate the satellite state vector. The diagonal elements of a priori covariance matrix $\left(P_{0}\right)$ associated with state vector were initialised as $(10 \mathrm{~m}, 10 \mathrm{~m}, 10 \mathrm{~m}, 0.1 \mathrm{~m} / \mathrm{s}, 0.1 \mathrm{~m} / \mathrm{s}$, $0.1 \mathrm{~m} / \mathrm{s})$. The process noise covariance matrix $(Q)$ is a result of effects of linearization errors, unmodelled dynamics and other approximations whereas the measurement covariance matrix $(R)$ depends on the variance of code phase observables for the BDS satellites (Carolipio et al., 2002; Grewal et al., 2007). The values of $R$ are competition sensitive and were not available in the literature for BDS satellites. Thus, unit measurement covariance $(R)$ was considered, whereas the diagonal elements of process noise covariance were initialised at $\left(0.001 \mathrm{~m}, 0.001 \mathrm{~m}, 0.001 \mathrm{~m}, 10^{-6} \mathrm{~m} / \mathrm{s}, 10^{-6} \mathrm{~m} / \mathrm{s}, 10^{-6} \mathrm{~m} / \mathrm{s}\right)$

Table 1. Orbital parameters for GEO and GSO BDS orbits.

\begin{tabular}{|c|c|c|c|c|}
\hline $\begin{array}{c}\text { Orbital } \\
\text { parameter }\end{array}$ & $\begin{array}{c}\text { Semi-major } \\
\text { axis (in m) }\end{array}$ & Eccentricity & $\begin{array}{c}\text { Inclination } \\
\text { (in deg) }\end{array}$ & $\begin{array}{c}\text { Argument of } \\
\text { perigee (in deg) }\end{array}$ \\
\hline GEO & 42164000.0 & 0.00 & 0.00 & 0.00 \\
\hline GSO & 42164000.0 & 0.02 & 55.00 & 0.00 \\
\hline
\end{tabular}


in the present study, as reported in the literature for GPS and NavIC satellites (Carolipio et al., 2002; Grewal et al., 200\%; Ramanathan and Chipade 2020).

The satellite orbits were determined using three different combinations of perturbation force models: (a) Kepler's model (KEP) (b) Perturbation force model Without Tidal and Relativistic (PWOTR) effects (c) Perturbation force model With Tidal and Relativistic effects (PWTR). The prediction interval was of $1 \mathrm{sec}$. for a total prediction period of 1 day. The GEO and GSO satellite orbits determined using EKF were compared with corresponding dynamic model of orbit determination using $4^{\text {th }}$ order Runge-Kutta numerical integration method.

Table 2 shows the RMSE in ECI X,Y,Z coordinates of satellite positions of GEO and GSO orbits when compared with dynamic orbit determination model, for all combinations of perturbation force models with varying values

Table 2. RMSE in the satellite positions of BDS satellites as compared with Dynamic Model after 1 day.

\begin{tabular}{|c|c|c|c|c|c|}
\hline $\begin{array}{l}\text { Force } \\
\text { model }\end{array}$ & $\begin{array}{l}\text { RAAN } \\
\text { (in deg) }\end{array}$ & Orbit & $\begin{array}{l}\text { ECI X } \\
\text { (in } \mathrm{cm})\end{array}$ & $\begin{array}{l}\text { ECI Y } \\
(\text { in } \mathrm{cm})\end{array}$ & $\begin{array}{c}\text { ECI Z } \\
(\text { in } \mathrm{cm})\end{array}$ \\
\hline \multirow{6}{*}{ KEP } & \multirow{2}{*}{0} & $\overline{\mathrm{GSO}}$ & 7.93 & 5.09 & 7.28 \\
\hline & & GEO & 7.93 & 8.88 & 0.00 \\
\hline & \multirow{2}{*}{120} & GSO & 5.73 & 7.49 & 7.28 \\
\hline & & GEO & 8.41 & 8.43 & 0.00 \\
\hline & \multirow{2}{*}{240} & GSO & 6.13 & 7.16 & 7.28 \\
\hline & & GEO & 8.89 & 7.91 & 0.00 \\
\hline \multirow{6}{*}{ PWOTR } & \multirow{2}{*}{0} & GSO & 7.93 & 8.50 & 12.51 \\
\hline & & GEO & 7.93 & 8.88 & 1.60 \\
\hline & \multirow{2}{*}{120} & GSO & 9.51 & 11.95 & 15.59 \\
\hline & & GEO & 8.41 & 8.43 & 1.58 \\
\hline & \multirow{2}{*}{240} & GSO & 9.61 & 6.73 & 11.46 \\
\hline & & GEO & 8.89 & 7.92 & 0.93 \\
\hline \multirow{6}{*}{ PWTR } & \multirow{2}{*}{0} & GSO & 7.93 & 8.50 & 12.51 \\
\hline & & GEO & 7.93 & 8.88 & 1.60 \\
\hline & \multirow{2}{*}{120} & GSO & 9.51 & 11.95 & 15.59 \\
\hline & & $\overline{\text { GEO }}$ & 8.41 & 8.43 & 1.58 \\
\hline & \multirow{2}{*}{240} & GSO & 9.61 & 6.73 & 11.46 \\
\hline & & GEO & 8.89 & 7.92 & 0.93 \\
\hline
\end{tabular}


of RAAN at $0^{\circ}, 120^{\circ}$, and $240^{\circ}$. RMSE of $7.93 \mathrm{~cm}$ to $8.89 \mathrm{~cm}$ and $7.91 \mathrm{~cm}$ to $8.88 \mathrm{~cm}$ was observed in ECI X and Y coordinates respectively; of BDS satellites in GEO when propagated using Keplerian model. RMSE of $5.73 \mathrm{~cm}$ to $7.93 \mathrm{~cm}$ and $5.09 \mathrm{~cm}$ to $7.49 \mathrm{~cm}$ was observed in ECI X and Y coordinates respectively; of BDS satellites in GSO when propagated using Keplerian model. RMSE of $7.28 \mathrm{~cm}$ was observed in prediction of ECEF Z coordinate of BDS satellite in GSO when propagated through Keplerian orbit. RMSE varied from $7.93 \mathrm{~cm}$ to $9.61 \mathrm{~cm}, 6.73 \mathrm{~cm}$ to $11.95 \mathrm{~cm}$ and $11.46 \mathrm{~cm}$ to $15.59 \mathrm{~cm}$ for ECI $\mathrm{X}, \mathrm{Y}$ and $\mathrm{Z}$ coordinates respectively; of satellite in BDS constellation in GSO when propagated through PWOTR and PWTR. RMSE varied from $7.93 \mathrm{~cm}$ to $8.89 \mathrm{~cm}, 7.92 \mathrm{~cm}$ to $8.88 \mathrm{~cm}$ and $0.93 \mathrm{~cm}$ to $1.60 \mathrm{~cm}$ for ECI X, Y and Z coordinates respectively; of satellite in BDS constellation in GEO when propagated through PWOTR and PWTR.

Figure 1 shows the variation in the residual error in ECI satellite coordinates $\mathrm{X}, \mathrm{Y}$ and $\mathrm{Z}$ when determined using EKF with perturbation model PWOTR for RAAN $240^{\circ}$. The oscillatory variation in residual error of satellite coordinates was observed over a period of 1 day in case of both GEO and GSO satellites (Fig. 1). This oscillatory variation in the residual error results in increased RMSE when perturbation effects were considered for orbit determination over Keplerian model (Table 2). Perturbation effects showed errors in satellite Z coordinate of GEO. WRS test was performed to assess the significance of perturbation forces included in the Keplerian model. The hypothesis that there is no significant difference in the median of residuals of estimated satellite positions using EKF with KEP and that using EKF with PWOTR was tested using WRS test against the hypothesis that median residuals of the EKF with KEP model were greater than that of EKF with PWOTR model. Table 3 shows the test statistic, $p$-values and
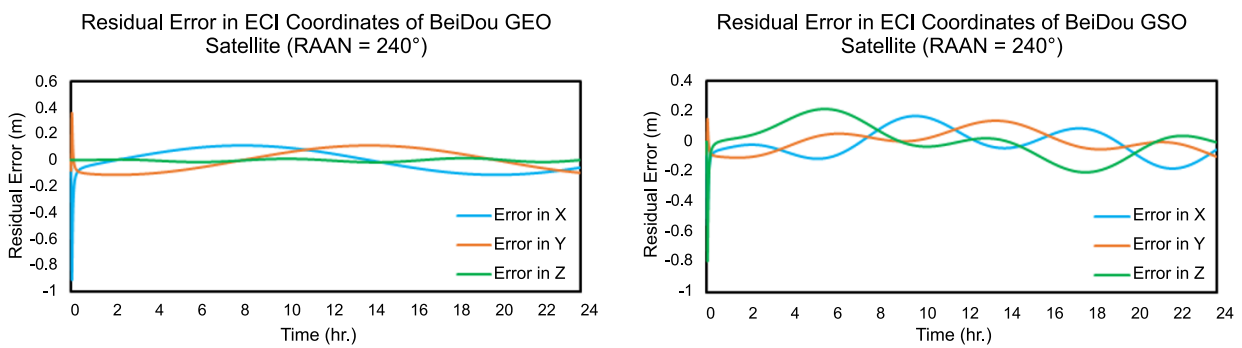

Fig. 1. Residual errors. 
decision of the WRS test performed for each satellite coordinate of GEO and GSO at RAAN $240^{\circ}$. The $p$-value $<0.01$ was observed in ECI X coordinate of GSO and ECI Z coordinate of GEO satellite of BDS at RAAN $240^{\circ}$, whereas $p$-value $>0.05$ was observed in ECI $\mathrm{Y}$ and $\mathrm{Z}$ coordinates of GSO and in ECI X and Y coordinates GEO satellites. Similar results were observed for BDS satellites at RAAN $0^{\circ}$ and $120^{\circ}$. Thus, median of residuals in estimated satellite coordinates using EKF with PWOTR was either significantly less than or equal to that of using EKF with KEP. This established that EKF with PWOTR performed as good as or better than EKF with KEP.

Inclusion of tidal and relativistic effects showed no difference in RMSE values when compared with that of PWOTR (Table 2). However, the difference of the order $10^{-9} \mathrm{~cm}$ was observed in RMSE values of satellite positions $\mathrm{X}, \mathrm{Y}$ and $\mathrm{Z}$ in ECI reference frame with inclusion of tidal and relativistic effects in the perturbation force model. The non-significance of the inclusion of tidal and relativistic effects in the perturbation force model for orbit prediction was further validated using the WRS test. The hypothesis that there is no significant difference in median of residuals of estimated satellite

Table 3. Test statistic and $p$-values of the WRS test (KEP vs. PWOTR for RAAN = $\left.240^{\circ}\right)$.

\begin{tabular}{|c|c|c|c|c|c|}
\hline Orbit & $\begin{array}{c}\text { Satellite } \\
\text { coordinate } \\
\text { in ECI }\end{array}$ & $\begin{array}{c}\text { Test } \\
\text { statistic }\end{array}$ & $p$-value & $\begin{array}{l}\text { Decision at } \\
5 \% \text { level of } \\
\text { significance }\end{array}$ & $\begin{array}{l}\text { Decision at } \\
1 \% \text { level of } \\
\text { significance }\end{array}$ \\
\hline GEO & \multirow{2}{*}{$\mathrm{X}$} & -0.065119 & 0.53 & $\begin{array}{l}\text { hypothesis is } \\
\text { not rejected }\end{array}$ & $\begin{array}{l}\text { hypothesis is } \\
\text { not rejected }\end{array}$ \\
\hline GSO & & 31.633354 & 0.00 & $\begin{array}{l}\text { hypothesis is } \\
\text { rejected }\end{array}$ & $\begin{array}{l}\text { hypothesis is } \\
\text { rejected }\end{array}$ \\
\hline GEO & \multirow{2}{*}{$\mathrm{Y}$} & 0.011736 & 0.50 & $\begin{array}{c}\text { hypothesis is } \\
\text { not rejected }\end{array}$ & $\begin{array}{l}\text { hypothesis is } \\
\text { not rejected }\end{array}$ \\
\hline GSO & & -13.879074 & 1.00 & $\begin{array}{l}\text { hypothesis is } \\
\text { not rejected }\end{array}$ & $\begin{array}{l}\text { hypothesis is } \\
\text { not rejected }\end{array}$ \\
\hline GEO & \multirow{2}{*}{ Z } & 26.457369 & 0.00 & $\begin{array}{l}\text { hypothesis is } \\
\text { rejected }\end{array}$ & $\begin{array}{l}\text { hypothesis is } \\
\text { rejected }\end{array}$ \\
\hline GSO & & -18.069100 & 1.00 & $\begin{array}{l}\text { hypothesis is } \\
\text { not rejected }\end{array}$ & $\begin{array}{l}\text { hypothesis is } \\
\text { not rejected }\end{array}$ \\
\hline
\end{tabular}


positions that are estimated using EKF with PWOTR and that using EKF with PWTR was tested using WRS test. Tables 4, 5 and 6 show the test statistic values, $p$-values and decision for the WRS test at $1 \%$ and $5 \%$ level of significance, performed for satellite $\mathrm{X}, \mathrm{Y}$ and $\mathrm{Z}$ coordinates of BDS satellite orbits with RAAN $0^{\circ}, 120^{\circ}$, and $240^{\circ}$, respectively. The $p$-value $>0.05$ was observed in all possible combinations of the BDS satellites and thus it established that there is no significant improvement in the orbit determination with inclusion of tidal and relativistic effects. Thus only EKF with PWOTR was used to validate the developed algorithm using IGS data in the next section.

Kolmogorov-Smirnov (K-S) test was performed to test the goodness of fit of the EKF estimated orbit with the dynamically estimated orbit using PWOTR as perturbation force model; independently for each satellite coordinate $\mathrm{X}, \mathrm{Y}$ and $\mathrm{Z}$. The hypothesis that there is no significant difference in the distributions of dynamically estimated and EKF estimated satellite coordinates was tested using K-S test. Table 7 shows the test statistic and $p$-values for the K-S test performed for satellite $\mathrm{X}, \mathrm{Y}$ and $\mathrm{Z}$ coordinates at RAAN $240^{\circ}$. The decision of the K-S test at $1 \%$ and $5 \%$ level of significance

Table 4. Test statistic and $p$-values of the WRS test (PWOTR vs. PWTR for RAAN = $\left.0^{\circ}\right)$.

\begin{tabular}{|c|c|c|c|c|c|}
\hline Orbit & $\begin{array}{c}\text { Satellite } \\
\text { coordinate } \\
\text { in ECI }\end{array}$ & $\begin{array}{c}\text { Test } \\
\text { statistic }\end{array}$ & $p$-value & $\begin{array}{l}\text { Decision at } \\
5 \% \text { level of } \\
\text { significance }\end{array}$ & $\begin{array}{l}\text { Decision at } \\
1 \% \text { level of } \\
\text { significance }\end{array}$ \\
\hline GEO & \multirow{2}{*}{$\mathrm{X}$} & -0.000120 & 0.50 & $\begin{array}{l}\text { hypothesis is } \\
\text { not rejected }\end{array}$ & $\begin{array}{l}\text { hypothesis is } \\
\text { not rejected }\end{array}$ \\
\hline GSO & & -0.000040 & 0.50 & $\begin{array}{l}\text { hypothesis is } \\
\text { not rejected }\end{array}$ & $\begin{array}{l}\text { hypothesis is } \\
\text { not rejected }\end{array}$ \\
\hline GEO & \multirow{2}{*}{ Y } & -0.000006 & 0.50 & $\begin{array}{l}\text { hypothesis is } \\
\text { not rejected }\end{array}$ & $\begin{array}{l}\text { hypothesis is } \\
\text { not rejected }\end{array}$ \\
\hline GSO & & -0.000103 & 0.50 & $\begin{array}{l}\text { hypothesis is } \\
\text { not rejected }\end{array}$ & $\begin{array}{l}\text { hypothesis is } \\
\text { not rejected }\end{array}$ \\
\hline GEO & \multirow{2}{*}{$\mathrm{Z}$} & 0.000052 & 0.50 & $\begin{array}{l}\text { hypothesis is } \\
\text { not rejected }\end{array}$ & $\begin{array}{l}\text { hypothesis is } \\
\text { not rejected }\end{array}$ \\
\hline GSO & & -0.000185 & 0.50 & $\begin{array}{l}\text { hypothesis is } \\
\text { not rejected }\end{array}$ & $\begin{array}{l}\text { hypothesis is } \\
\text { not rejected }\end{array}$ \\
\hline
\end{tabular}


Table 5. Test statistic and $p$-values of the WRS test (PWOTR vs. PWTR for RAAN = $120^{\circ}$ ).

\begin{tabular}{|c|c|c|c|c|c|}
\hline Orbit & $\begin{array}{c}\text { Satellite } \\
\text { coordinate } \\
\text { in ECI }\end{array}$ & $\begin{array}{c}\text { Test } \\
\text { statistic }\end{array}$ & $p$-value & $\begin{array}{l}\text { Decision at } \\
5 \% \text { level of } \\
\text { significance }\end{array}$ & $\begin{array}{l}\text { Decision at } \\
1 \% \text { level of } \\
\text { significance }\end{array}$ \\
\hline GEO & \multirow{2}{*}{$\mathrm{X}$} & -0.048459 & 0.52 & $\begin{array}{l}\text { hypothesis is } \\
\text { not rejected }\end{array}$ & $\begin{array}{l}\text { hypothesis is } \\
\text { not rejected }\end{array}$ \\
\hline GSO & & -0.000164 & 0.50 & $\begin{array}{l}\text { hypothesis is } \\
\text { not rejected }\end{array}$ & $\begin{array}{l}\text { hypothesis is } \\
\text { not rejected }\end{array}$ \\
\hline GEO & \multirow{2}{*}{ Y } & -0.081781 & 0.53 & $\begin{array}{c}\text { hypothesis is } \\
\text { not rejected }\end{array}$ & $\begin{array}{l}\text { hypothesis is } \\
\text { not rejected }\end{array}$ \\
\hline GSO & & 0.000011 & 0.50 & $\begin{array}{l}\text { hypothesis is } \\
\text { not rejected }\end{array}$ & $\begin{array}{l}\text { hypothesis is } \\
\text { not rejected }\end{array}$ \\
\hline GEO & \multirow{2}{*}{$\mathrm{Z}$} & 0.000028 & 0.50 & $\begin{array}{l}\text { hypothesis is } \\
\text { not rejected }\end{array}$ & $\begin{array}{l}\text { hypothesis is } \\
\text { not rejected }\end{array}$ \\
\hline GSO & & -0.000013 & 0.50 & $\begin{array}{l}\text { hypothesis is } \\
\text { not rejected }\end{array}$ & $\begin{array}{c}\text { hypothesis is } \\
\text { not rejected }\end{array}$ \\
\hline
\end{tabular}

Table 6. Test statistic and $p$-values of the WRS test (PWOTR vs. PWTR for RAAN $=$ $240^{\circ}$ ).

\begin{tabular}{|c|c|c|c|c|c|}
\hline Orbit & $\begin{array}{l}\text { Satellite } \\
\text { coordinate } \\
\text { in ECI }\end{array}$ & $\begin{array}{c}\text { Test } \\
\text { statistic }\end{array}$ & $p$-value & $\begin{array}{l}\text { Decision at } \\
5 \% \text { level of } \\
\text { significance }\end{array}$ & $\begin{array}{l}\text { Decision at } \\
1 \% \text { level of } \\
\text { significance }\end{array}$ \\
\hline GEO & \multirow{2}{*}{$\mathrm{X}$} & 0.000098 & 0.50 & $\begin{array}{c}\text { hypothesis is } \\
\text { not rejected }\end{array}$ & $\begin{array}{c}\text { hypothesis is } \\
\text { not rejected }\end{array}$ \\
\hline GSO & & 0.000074 & 0.50 & $\begin{array}{l}\text { hypothesis is } \\
\text { not rejected }\end{array}$ & $\begin{array}{l}\text { hypothesis is } \\
\text { not rejected }\end{array}$ \\
\hline GEO & \multirow{2}{*}{ Y } & -0.000025 & 0.50 & $\begin{array}{l}\text { hypothesis is } \\
\text { not rejected }\end{array}$ & $\begin{array}{l}\text { hypothesis is } \\
\text { not rejected }\end{array}$ \\
\hline GSO & & -0.000010 & 0.50 & $\begin{array}{l}\text { hypothesis is } \\
\text { not rejected }\end{array}$ & $\begin{array}{l}\text { hypothesis is } \\
\text { not rejected }\end{array}$ \\
\hline GEO & \multirow{2}{*}{ Z } & 0.000148 & 0.50 & $\begin{array}{l}\text { hypothesis is } \\
\text { not rejected }\end{array}$ & $\begin{array}{l}\text { hypothesis is } \\
\text { not rejected }\end{array}$ \\
\hline GSO & & 0.000048 & 0.50 & $\begin{array}{l}\text { hypothesis is } \\
\text { not rejected }\end{array}$ & $\begin{array}{l}\text { hypothesis is } \\
\text { not rejected }\end{array}$ \\
\hline
\end{tabular}


is as shown in Table 7. It was observed that $p$-value $>0.05$ for all possible combinations of BDS satellite orbits at RAAN $240^{\circ}$. The test statistic value of K-S test for Z coordinate of GEO satellite was observed to be comparatively high due to effect of perturbation forces. Similar results were achieved when RAAN was varied to $0^{\circ}$ and $120^{\circ}$. This indicates that goodness of fit of PWOTR as a perturbation force model is better as compared to PWTR, when EKF is used for satellite orbit determination.

Table 7. Test statistic and $p$-values of the K-S test $\left(\mathrm{RAAN}=240^{\circ}\right)$.

\begin{tabular}{|c|c|c|c|c|c|}
\hline Orbit & $\begin{array}{c}\text { Satellite } \\
\text { coordinate } \\
\text { in ECI }\end{array}$ & $\begin{array}{c}\text { Test } \\
\text { statistic }\end{array}$ & $p$-value & $\begin{array}{l}\text { Decision at } \\
5 \% \text { level of } \\
\text { significance }\end{array}$ & $\begin{array}{l}\text { Decision at } \\
1 \% \text { level of } \\
\text { significance }\end{array}$ \\
\hline GEO & \multirow{2}{*}{$\mathrm{X}$} & 0.000023 & 1.00 & $\begin{array}{l}\text { hypothesis is } \\
\text { not rejected }\end{array}$ & $\begin{array}{l}\text { hypothesis is } \\
\text { not rejected }\end{array}$ \\
\hline GSO & & 0.000035 & 1.00 & $\begin{array}{l}\text { hypothesis is } \\
\text { not rejected }\end{array}$ & $\begin{array}{l}\text { hypothesis is } \\
\text { not rejected }\end{array}$ \\
\hline GEO & \multirow{2}{*}{$\mathrm{Y}$} & 0.000023 & 1.00 & $\begin{array}{l}\text { hypothesis is } \\
\text { not rejected }\end{array}$ & $\begin{array}{l}\text { hypothesis is } \\
\text { not rejected }\end{array}$ \\
\hline GSO & & 0.000023 & 1.00 & $\begin{array}{l}\text { hypothesis is } \\
\text { not rejected }\end{array}$ & $\begin{array}{l}\text { hypothesis is } \\
\text { not rejected }\end{array}$ \\
\hline GEO & \multirow{2}{*}{ Z } & 0.003669 & 0.61 & $\begin{array}{c}\text { hypothesis is } \\
\text { not rejected }\end{array}$ & $\begin{array}{l}\text { hypothesis is } \\
\text { not rejected }\end{array}$ \\
\hline GSO & & 0.000046 & 1.00 & $\begin{array}{l}\text { hypothesis is } \\
\text { not rejected }\end{array}$ & $\begin{array}{l}\text { hypothesis is } \\
\text { not rejected }\end{array}$ \\
\hline
\end{tabular}

\subsection{Orbit determination with IGS station data for BDS GEO and GSO satellites}

The developed EKF based statistical orbit determination algorithm using PWOTR perturbation force model was further applied to real time data collected at IGS station. International GNSS Service (IGS) provides high quality GNSS data products openly and data are regularly collected at various stations all over the world. One of such stations is located at IISc, Banglore, India $\left(13^{\circ} 01^{\prime} \mathrm{N}, 77^{\circ} 34^{\prime} \mathrm{E}\right)$. The navigation data for BDS was downloaded for 5 consecutive days spanning 28 September to 2 October, 2019 from IGS repository (https://cddis.nasa.gov/gnss/data) and was used to determine the coordinates of GEO and GSO satellites of BDS con- 
stellation. The satellites $\mathrm{C} 01, \mathrm{C} 02, \mathrm{C} 03, \mathrm{C} 04$, and $\mathrm{C} 05$ of BDS constellation were in GEO whereas satellites C06, C07, C08, C09, C10, and C13 of BDS constellation were in GSO (Qin et al., 2019). The orbit of satellites C02 (GEO) and C09 (GSO) of BDS constellation was determined using EKF with PWOTR and were compared with actual satellite coordinates computed using available navigation data, in the present study. The satellite coordinates were predicted at time step of $60 \mathrm{sec}$. for each day data. Tables 8 and 9 show the RMS error in the estimated satellite coordinates of GEO and GSO satellites of BDS constellation after $6 \mathrm{hrs}, 12 \mathrm{hrs}, 18 \mathrm{hrs}$, and $24 \mathrm{hrs}$ of prediction, respectively. RMS errors of $3.89 \mathrm{~km}, 4.20 \mathrm{~km}$ and $6.66 \mathrm{~km}$ were observed in ECI X, Y, and Z satellite position coordinates of GSO (C09), respectively whereas the RMS errors for GEO (C02) satellite were

Table 8. RMS error in estimated satellite coordinates of GEO (C02) using IGS data.

\begin{tabular}{|c|c|c|c|c|}
\hline \multirow{2}{*}{ Day } & \multirow{2}{*}{ Time } & \multicolumn{3}{|c|}{ RMS error (in km) } \\
\cline { 2 - 5 } & & ECI X & ECI Y & ECI Z \\
\hline \multirow{4}{*}{28 Sept. 2019 } & $6 \mathrm{hrs}$ & 2.91 & 2.28 & 11.98 \\
\cline { 2 - 5 } & $12 \mathrm{hrs}$ & 3.23 & 2.27 & 8.81 \\
\cline { 2 - 5 } & $18 \mathrm{hrs}$ & 3.81 & 3.91 & 7.48 \\
\cline { 2 - 5 } & $24 \mathrm{hrs}$ & 3.87 & 4.20 & 6.68 \\
\hline \multirow{4}{*}{ Sept. 2019 } & $6 \mathrm{hrs}$ & 3.00 & 2.13 & 11.98 \\
\cline { 2 - 5 } & $12 \mathrm{hrs}$ & 3.21 & 2.32 & 8.81 \\
\cline { 2 - 5 } & $18 \mathrm{hrs}$ & 3.97 & 3.77 & 7.47 \\
\cline { 2 - 5 } & $24 \mathrm{hrs}$ & 3.89 & 4.19 & 6.67 \\
\hline \multirow{4}{*}{ Sept. 2019 } & $6 \mathrm{hrs}$ & 2.96 & 2.14 & 11.98 \\
\cline { 2 - 5 } & $12 \mathrm{hrs}$ & 3.22 & 2.33 & 8.80 \\
\cline { 2 - 5 } & $18 \mathrm{hrs}$ & 3.96 & 3.80 & 7.47 \\
\cline { 2 - 5 } & $24 \mathrm{hrs}$ & 3.89 & 4.19 & 6.66 \\
\hline \multirow{3}{*}{ Oct. 2019 } & $6 \mathrm{hrs}$ & 2.91 & 2.16 & 11.97 \\
\cline { 2 - 5 } & $12 \mathrm{hrs}$ & 3.24 & 2.33 & 8.80 \\
\cline { 2 - 5 } & $18 \mathrm{hrs}$ & 3.94 & 3.83 & 7.46 \\
\cline { 2 - 5 } & $24 \mathrm{hrs}$ & 3.89 & 4.20 & 6.65 \\
\hline \multirow{3}{*}{2 Oct. 2019 } & $6 \mathrm{hrs}$ & 2.87 & 2.17 & 11.97 \\
\cline { 2 - 5 } & $12 \mathrm{hrs}$ & 3.25 & 2.32 & 8.79 \\
\cline { 2 - 5 } & $18 \mathrm{hrs}$ & 3.93 & 3.86 & 7.45 \\
\cline { 2 - 5 } & $24 \mathrm{hrs}$ & 3.89 & 4.20 & 6.64 \\
\hline
\end{tabular}


$0.75 \mathrm{~km}, 2.53 \mathrm{~km}$, and $1.91 \mathrm{~km}$ respectively in ECI X, Y and Z coordinates; after $24 \mathrm{hrs}$ of prediction. RMS errors were observed to increase with prediction time interval from $6 \mathrm{hrs}$ to $24 \mathrm{hrs}$ in ECI X and ECI Y coordinates of GEO satellite, whereas decrease in RMS error was observed with time in ECI Z coordinate of GEO satellite. For GSO satellite, increase in RMS error of ECI Y, whereas, decrease in RMS error of ECI X coordinate was observed with prediction time interval. ECI Z coordinate of GSO satellite showed an initial increase and later decrease in RMS error with prediction time interval, indicating the oscillatory variation in residuals of satellite coordinates.

Broadcast ephemeris provided by the IGS station navigation data were used to compute actual satellite coordinates. Seppänen (2010) has reported

Table 9. RMS error in estimated satellite coordinates of GSO (C09) using IGS data.

\begin{tabular}{|c|c|c|c|c|}
\hline \multirow{2}{*}{ Day } & \multirow{2}{*}{ Time } & \multicolumn{3}{|c|}{ RMS error (in km) } \\
\cline { 2 - 5 } & & ECI X & ECI Y & ECI Z \\
\hline \multirow{4}{*}{28 Sept. 2019 } & $6 \mathrm{hrs}$ & 1.42 & 0.70 & 0.60 \\
\cline { 2 - 5 } & $12 \mathrm{hrs}$ & 1.02 & 0.76 & 0.61 \\
\cline { 2 - 5 } & $18 \mathrm{hrs}$ & 0.84 & 2.47 & 1.86 \\
\cline { 2 - 5 } & $24 \mathrm{hrs}$ & 0.74 & 2.52 & 1.85 \\
\hline \multirow{4}{*}{ Sept. 2019 } & $6 \mathrm{hrs}$ & 1.45 & 0.63 & 0.59 \\
\cline { 2 - 5 } & $12 \mathrm{hrs}$ & 1.04 & 0.62 & 0.59 \\
\cline { 2 - 5 } & $18 \mathrm{hrs}$ & 0.87 & 2.52 & 1.92 \\
\cline { 2 - 5 } & $24 \mathrm{hrs}$ & 0.76 & 2.38 & 1.79 \\
\hline \multirow{3}{*}{ Sept. 2019 } & $6 \mathrm{hrs}$ & 1.44 & 0.68 & 0.60 \\
\cline { 2 - 5 } & $12 \mathrm{hrs}$ & 1.04 & 0.76 & 0.69 \\
\cline { 2 - 5 } & $18 \mathrm{hrs}$ & 0.86 & 2.69 & 2.05 \\
\cline { 2 - 5 } & $24 \mathrm{hrs}$ & 0.76 & 2.47 & 1.88 \\
\hline \multirow{3}{*}{1 Oct. 2019 } & $6 \mathrm{hrs}$ & 1.43 & 0.83 & 0.69 \\
\cline { 2 - 5 } & $12 \mathrm{hrs}$ & 1.03 & 0.94 & 0.81 \\
\cline { 2 - 5 } & $18 \mathrm{hrs}$ & 0.86 & 2.88 & 2.19 \\
\cline { 2 - 5 } & $24 \mathrm{hrs}$ & 0.76 & 2.61 & 1.99 \\
\hline \multirow{3}{*}{2 Oct. 2019 } & $6 \mathrm{hrs}$ & 1.43 & 0.78 & 0.67 \\
\cline { 2 - 5 } & $12 \mathrm{hrs}$ & 1.03 & 0.92 & 0.81 \\
\cline { 2 - 5 } & $18 \mathrm{hrs}$ & 0.85 & 2.97 & 2.25 \\
\cline { 2 - 5 } & $24 \mathrm{hrs}$ & 0.75 & 2.69 & 2.04 \\
\hline
\end{tabular}


orbit prediction error of order $50 \mathrm{~m}$ where precise ephemeris was used to compute reference satellite coordinates. Seppänen (2010) also reported that the prediction error in satellite orbit was an order of magnitude worse when broadcast ephemeris was used to compute actual satellite coordinates. Several studies have reported $\mathrm{km}$ level prediction error in orbit determination of GSO and GEO satellites (Davis et al., 2002; Hwang et al., 2013; Shen et al., 2018). Thus, our findings are consistent with that reported in the literature. Therefore, these can be used in future navigation applications such as extended ephemeris technology.

The RMS error in the satellite velocity in ECI X, Y and Z directions of GSO and GEO satellites were also examined along with errors in satellite positioning. The average RMS error of $9.11 \mathrm{~m} / \mathrm{s}, 22.79 \mathrm{~m} / \mathrm{s}$ and $32.21 \mathrm{~m} / \mathrm{s}$ in ECI X, Y and Z direction, respectively of GSO (C09) satellite velocity

Table 10. Test statistic and $p$-values of the K-S test for GEO (C02) using IGS data.

\begin{tabular}{|c|c|c|c|c|c|}
\hline Day & $\begin{array}{l}\text { Satellite } \\
\text { coordinate } \\
\text { in ECI }\end{array}$ & $\begin{array}{c}\text { Test } \\
\text { statistic }\end{array}$ & $p$-value & $\begin{array}{c}\text { Decision at } \\
5 \% \text { level of } \\
\text { significance } \\
\text { about } \\
\text { hypothesis }\end{array}$ & $\begin{array}{c}\text { Decision at } \\
1 \% \text { level of } \\
\text { significance } \\
\text { about } \\
\text { hypothesis }\end{array}$ \\
\hline 28 Sept. 2019 & \multirow{5}{*}{$\mathrm{X}$} & 0.001390 & 1.00 & not rejected & not rejected \\
\hline 29 Sept. 2019 & & 0.001390 & 1.00 & not rejected & not rejected \\
\hline 30 Sept. 2019 & & 0.001390 & 1.00 & not rejected & not rejected \\
\hline 1 Oct. 2019 & & 0.001390 & 1.00 & not rejected & not rejected \\
\hline 2 Oct. 2019 & & 0.002085 & 1.00 & not rejected & not rejected \\
\hline 28 Sept. 2019 & \multirow{5}{*}{$\mathrm{Y}$} & 0.001390 & 1.00 & not rejected & not rejected \\
\hline 29 Sept. 2019 & & 0.001390 & 1.00 & not rejected & not rejected \\
\hline 30 Sept. 2019 & & 0.001390 & 1.00 & not rejected & not rejected \\
\hline 1 Oct. 2019 & & 0.001390 & 1.00 & not rejected & not rejected \\
\hline 2 Oct. 2019 & & 0.001390 & 1.00 & not rejected & not rejected \\
\hline 28 Sept. 2019 & \multirow{5}{*}{$\mathrm{Z}$} & 0.014593 & 1.00 & not rejected & not rejected \\
\hline 29 Sept. 2019 & & 0.013899 & 1.00 & not rejected & not rejected \\
\hline 30 Sept. 2019 & & 0.014593 & 1.00 & not rejected & not rejected \\
\hline 1 Oct. 2019 & & 0.014593 & 1.00 & not rejected & not rejected \\
\hline 2 Oct. 2019 & & 0.015288 & 1.00 & not rejected & not rejected \\
\hline
\end{tabular}


vector was observed whereas RMS error of $5.63 \mathrm{~m} / \mathrm{s}, 39.71 \mathrm{~m} / \mathrm{s}$ and $9.24 \mathrm{~m} / \mathrm{s}$ in ECI X, Y and $\mathrm{Z}$ direction, respectively of GEO (C02) satellite velocity vector was observed after $1 \mathrm{hr}$ of prediction. The average RMS error increased to $28.46 \mathrm{~m} / \mathrm{s}, 16.60 \mathrm{~m} / \mathrm{s}$ and $23.29 \mathrm{~m} / \mathrm{s}$ in ECI X, Y and Z direction, respectively of GSO (C09) satellite velocity after $24 \mathrm{hrs}$ of prediction. Whereas, the average RMS error increased to $28.44 \mathrm{~m} / \mathrm{s}, 28.48 \mathrm{~m} / \mathrm{s}$ and $9.11 \mathrm{~m} / \mathrm{s}$ in ECI X, Y and Z direction, respectively of GEO (C02) satellite velocity after $24 \mathrm{hrs}$ of prediction.

The K-S test was used to test the goodness of fit of EKF with PWOTR algorithm to the IGS data. The hypothesis that there is no significant difference in the distributions of satellite coordinates computed using navigation data and EKF estimated satellite coordinates was tested using K-S test. Tables 10 and 11 show the test statistic, $p$-value and decision of the K-S

Table 11. Test statistic and $p$-values of the K-S test for GSO (C09) using IGS data.

\begin{tabular}{|c|c|c|c|c|c|}
\hline Day & $\begin{array}{c}\text { Satellite } \\
\text { coordinate } \\
\text { in ECI }\end{array}$ & $\begin{array}{c}\text { Test } \\
\text { statistic }\end{array}$ & $p$-value & $\begin{array}{c}\text { Decision at } \\
5 \% \text { level of } \\
\text { significance } \\
\text { about } \\
\text { hypothesis }\end{array}$ & $\begin{array}{c}\text { Decision at } \\
1 \% \text { level of } \\
\text { significance } \\
\text { about } \\
\text { hypothesis }\end{array}$ \\
\hline 28 Sept. 2019 & \multirow{5}{*}{$\mathrm{X}$} & 0.001390 & 1.00 & not rejected & not rejected \\
\hline 29 Sept. 2019 & & 0.001389 & 1.00 & not rejected & not rejected \\
\hline 30 Sept. 2019 & & 0.001389 & 1.00 & not rejected & not rejected \\
\hline 1 Oct. 2019 & & 0.001390 & 1.00 & not rejected & not rejected \\
\hline 2 Oct. 2019 & & 0.001390 & 1.00 & not rejected & not rejected \\
\hline 28 Sept. 2019 & \multirow{5}{*}{$\mathrm{Y}$} & 0.001390 & 1.00 & not rejected & not rejected \\
\hline 29 Sept. 2019 & & 0.002083 & 1.00 & not rejected & not rejected \\
\hline 30 Sept. 2019 & & 0.002085 & 1.00 & not rejected & not rejected \\
\hline 1 Oct. 2019 & & 0.002780 & 1.00 & not rejected & not rejected \\
\hline 2 Oct. 2019 & & 0.002085 & 1.00 & not rejected & not rejected \\
\hline 28 Sept. 2019 & \multirow{5}{*}{$\mathrm{Z}$} & 0.001390 & 1.00 & not rejected & not rejected \\
\hline 29 Sept. 2019 & & 0.001389 & 1.00 & not rejected & not rejected \\
\hline 30 Sept. 2019 & & 0.001389 & 1.00 & not rejected & not rejected \\
\hline 1 Oct. 2019 & & 0.001390 & 1.00 & not rejected & not rejected \\
\hline 2 Oct. 2019 & & 0.001390 & 1.00 & not rejected & not rejected \\
\hline
\end{tabular}


test performed for GEO and GSO satellites of BDS constellation after $24 \mathrm{hrs}$ of prediction, respectively. The K-S test was observed to be significant at both, $1 \%$ and $5 \%$ level of significance with $p$-value $>0.05$. This indicates goodness of fit of estimated BDS orbits using EKF with PWOTR with IGS navigation data.

\section{Conclusions}

Extended Kalman filter was proposed to determine geostationary and geosynchronous satellite orbits of BDS constellation. Keplerian model and Perturbation force model affecting the satellite positions were studied. Perturbation forces such as solar radiation pressure, harmonics due to Earth's gravity potential, solar and lunar attraction forces had significant effect on the satellite position, whereas, tidal and relativistic effects did not show significant effect on the satellite position. The EKF predictions through perturbation force model were better than or as good as Keplerian force model. Centimetre-level accuracy was achieved to predict BDS orbits, defined with an assumed set of orbital parameters; using EKF algorithm when compared with dynamically determined orbit. Kilometre level accuracy was achieved to determine geostationary and geosynchronous orbits of BDS constellation using proposed EKF algorithm with PWOTR perturbation force model with real data logged at IGS stations. Kolmogorov-Smirnov test for EKF with PWOTR algorithm reported $p$-value $>0.05$ indicating goodness of fit of predicted BDS orbits using EKF with PWOTR. There is a scope to improve the algorithm with better prediction accuracy up to sub-kilometre level using precise ephemeris and clock parameters and with less time for computations of future prediction due to complexities of perturbation force model. The developed algorithm thus gives encouraging results that can be used in future technologies for GNSS receiver developments such as selfassisted ephemeris technology.

Acknowledgements. This work was carried out in collaboration with the Department of Statistics and Centre for Advanced Studies, Savitribai Phule Pune University, Pune, India under the Ph.D. program. The authors are thankful to Shri N. M. Desai, Director, Space Applications Centre (SAC), ISRO, Ahmedabad, India and Shri D. K. Das, Former Director, SAC (ISRO), Ahmedabad for providing the opportunity to carry out this work. The authors are very grateful to Dr. M. R. Pandya, Head, AED/SAC; Dr. B. K. 
Bhattacharya, Group Director/BPSG/SAC; and Dr. Raj Kumar, Director, National Remote Sensing Centre (NRSC), ISRO, Hyderabad, India for their constant support and encouragement towards this work. The authors also extend their gratitude towards all those who knowingly and unknowingly supported towards completion of this work. They are also thankful to anonymous reviewers for their valuable suggestions which has improved the manuscript substantially.

\section{References}

Aghav S. T., Gangal S. A., 2014: Simplified Orbit Determination Algorithm for Low Earth Orbit Satellites using Space born GPS Navigation Sensor. Artif. Satell., 49, 2, 81-99, doi: 10.2478/arsa-2014-0007.

Carolipio E. M., Pandya N. K., Grewal M. S., 2002: GEO Orbit Determination via Covariance Analysis with a Known Clock Error. Navig., 48, 4, 255-260, doi: 10.1002/j. 2161-4296.2001.tb00249.x.

Chandrasekhar M. V., Rajarajan D., Satyanarayana G., Tirmal N., Rathnakara S. C., Ganeshan A. S., 2015: Modernized IRNSS Broadcast Ephemeris Parameters. Control Theory and Informatics, 5, 2, 1-9.

Chobotov V. A., 2002: Orbital Mechanics. $3^{\text {rd }}$ ed., AIAA, Virginia, doi : 10.2514/4.862 250.

Davis G., Moreau M., Carpenter R., Bauer F., 2002: GPS-based Navigation and Orbit Determination for the AMSAT AO-40 Satellite. AIAA Guidance, Navigation and Control Conference and Exhibit, 5-8 Aug. 2002, Monterey, California, doi: $10.2514 / 6.2002-5004$.

Grewal M. S., Weill L. R., Andrews A. P., 2007: Global Positioning System, Inertial Navigation and Integration, $2^{\text {nd }}$ ed., John Willey and Sons Inc., NJ, USA, 416 p.

Hein G. W., Su H., Eissfeller B., 1997: Orbit determination of geosynchronous satellites of a European Satellite Navigation System (ENSS). Proc. $12^{\text {th }}$ Int. Sym. 'Space Flight Dynamics', Darmstadt, Germany, June 2-6, 1997, 59-64.

Huang Y. S., Tsai M. L., 2008: The impact of Compass/BeiDou-2 on Future GNSS: A Perspective from Asia. Proc. ION-GNSS $21^{\text {st }}$ Int. Tech. Meet., September 16-19, 2008, Savannah, GA, 2227-2238.

Hwang Y., Lee B. S., Kim B. Y., Kim H. Y., Kim K., 2013: Validation of Geostationary Satellite Orbit Determination using Single-Station Antenna Tracking Data. J. Spacecr. Rockets, 50, 6, 1248-1255, doi: 10.2514/1.A32334.

Kavitha S., Prasanta M., Babu R., Ratnakara S. C., Ganeshan A. S., 2015: Adaptive Extended Kalman filter for Orbit Estimation of GEO Satellites. J. Environ. Earth Sci., 5, 3, 1-10.

Kazmierski K., Zajdel R., Sośnica K., 2020: Evolution of orbit and clock quality for realtime multi-GNSS solutions. GPS Solut., 24, 111, doi: 10.1007/s10291-020-010 $26-6$.

Mashiku A. K., 2013: Information Measures for Statistical Orbit Determination. Ph.D. Dissertation, Purdue University, Indiana, https://docs.lib.purdue.edu/open_ac 
cess_dissertations/7.

Montenbruck O., Gill E., 2005: Satellite Orbits: Models, Methods and Applications. $3^{\text {rd }}$ ed., Springer, Heidelberg, 369 p.

Qin Z., Huang G., Zhang Q., Wang L., Yan X., Kang Y., Wang X., Xie S., 2019: A Method to Determine BeiDou GEO/IGSO Orbital Maneuver Time Periods. Sensors, 19, 12, 2675, doi: $10.3390 /$ s19122675.

Ramanathan T. V., Chipade R. A., 2020: Statistical Orbit Determination Algorithm for Satellites in Indian Navigation Constellation (NavIC): Towards Extended Ephemeris Technology for NavIC Receiver. Artificial Satellites, 55, 2, 29-40, doi: 10.2478/ar sa-2020-0003.

Seppänen M., 2010: GPS satellite orbit prediction (GPS-Satelliitin radan ennustaminen). M.Sc. Thesis, Tampere University of Technology, Finland (in Finnish with English abstract).

Seppänen M., Perälä T., Piché R., 2011: Autonomous Satellite Orbit Prediction. Proceedings of the 2011 International Technical Meeting of the Institute of Navigation, January 24-26, 2011, San Diego, CA, 554-564.

Shen Z., Peng J., Liu W., Wang F., Zhu S., Wu Z., 2018: Self-Assisted First-Fix Method for A-BDS Receivers with Medium- and Long-term Ephemeris Extension. Hindawi Math. Probl. Eng., 2018, 5325034, 1-14, doi: 10.1155/2018/5325034.

Stacey P., Ziebart M., 2011: Long-Term Extended Ephemeris Prediction for Mobile Devices. Proceedings of the 24th International Technical Meeting of the Satellite Division of the Institute of Navigation (ION GNSS 2011), Portland, OR, September 2011, 3235-3244.

Tapley B. D., Schutz B. E., Born G. H., 2004: Statistical Orbit Determination. Elsevier Academic Press, USA, 547 p., doi: 10.1016/B978-0-12-683630-1.X5019-X.

Xiaoganag X., Mingquan L., 2017: Broadcast Ephemeris Model of the BeiDou Navigation Satellite System. J. Eng. Sci. Technol. Rev., 10, 4, 65-71, doi : 10.25103/jestr. 10 4.09 .

Zhang W., Venkatasubramanian V., Liu H., Pathak M., Han S., 2008: SiRF InstantFix II Technology. Proceedings of the 21st International Technical Meeting of the Satellite Division of The Institute of Navigation (ION GNSS 2008), Savannah, GA, Sept. 1619, 2008, 1840-1847. 